\title{
Adolescent idiopathic scoliosis (AIS): a multifactorial cascade concept for pathogenesis and embryonic origin
}

\author{
R. Geoffrey Burwell ${ }^{1 *}$, Emma M. Clark², Peter H. Dangerfield ${ }^{3}$ and Alan Moulton ${ }^{4}$
}

\begin{abstract}
This paper formulates a novel multifactorial Cascade Concept for the pathogenesis of adolescent idiopathic scoliosis (AIS). This Concept stems from the longitudinal findings of Clark et al. (J Bone Miner Res 29(8):1729-36, 2014) who identified leptin body composition factors at 10 years of age associated with a scoliosis deformity found at 15 years. We interpret these findings in the light of some concepts for AIS pathogenesis. In particular, we speculate that the leptin body composition effect is linked to central nervous system development and the initiation of the asynchronous neuro-osseous growth mechanism that involves the creation of a neuraxis tether of relative anterior vertebral overgrowth. The latter mechanism in combination with age and gender-related anatomical variants of vertebral backward tilt (dorsal shear concept), human upright posture, adolescent growth factors, Hueter-Volkmann effect in vertebrae and vertebral bone mass abnormalities, lead to AIS, possibly both initiation and progression of scoliosis curvatures. Being multifactorial, while the Cascade Concept cannot be tested for all its components, some components should be testable by the method of numerical simulation.

Clark et al. (J Bone Miner Res 29(8):1729-36, 2014) also suggested the origin of scoliosis was in the embryonic stages of life from cell types, including adipocytes and osteoblasts, derived from the same progenitor cells, and myoblasts from mesodermal somites. The involvement of cell types from different developmental origins suggests a process acting in embryonic life at a similar time, probably environmental, as previously proposed from anthropometric studies. As a Complex disease, AIS will involve genetic, environmental and life style factors operating in development and growth; this possibility needs evaluating in epidemiological studies.
\end{abstract}

Keywords: Scoliosis, Aetiology, Pathogenesis, Fat, Muscle, Embryology, Epidemiology

\section{Background}

While there is no agreed theory for the pathogenesis of adolescent idiopathic scoliosis (AIS), several concepts attempt to do so, focusing on specific pathogenetic processes [1-3]. Here, we suggest a novel speculative multifactorial Cascade Concept for AIS pathogenesis. It stems from the longitudinal findings of Clark et al. [4] which we interpret here in the light of some pathogenetic concepts for AIS (Fig. 1). Preliminary accounts of the concept have been presented $[3,5,6]$.

\footnotetext{
* Correspondence: gburwell@tiscali.co.uk

'Centre for Spinal Studies and Surgery, Queen's Medical Centre, Nottingham

University Hospitals Trust, Nottingham, UK

Full list of author information is available at the end of the article
}

\section{The Avon longitudinal study of parents and children} (ALSPAC) and idiopathic scoliosis

Clark et al. [4] identified factors at 10 years of age that were associated with a scoliosis deformity identified at 15 years of age. These factors are low fat mass, low lean mass, low circulating leptin and high circulating adiponectin levels. We speculate that this leptin body composition effect in AIS is linked to central nervous system development, as shown in mice for the brain [7] and, in particular to impaired neuraxis growth as it stretches in adapting to vertebral column growth as the child grows in height. 


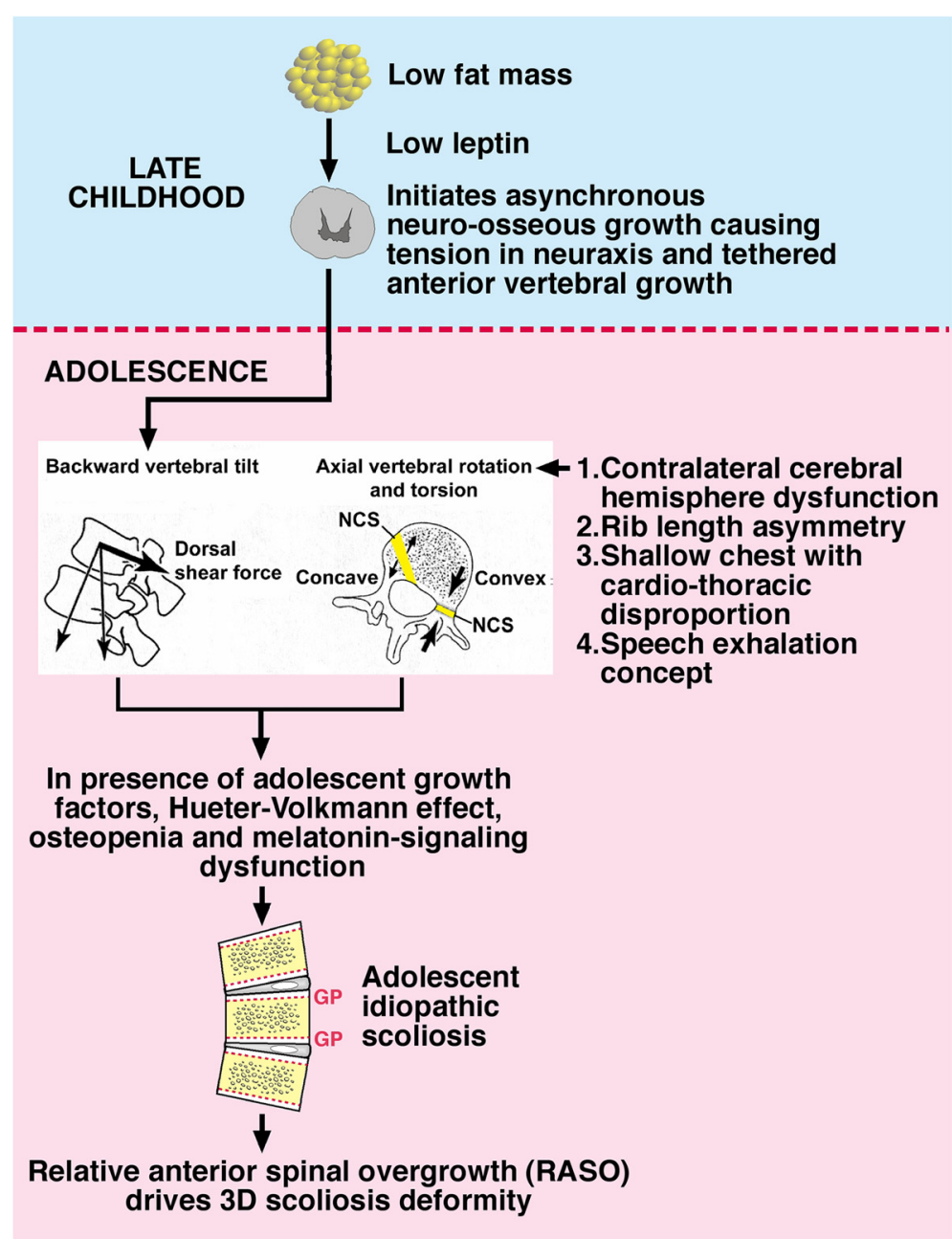

Fig. 1 Cascade Concept for AIS pathogenesis based on the findings of Clark et al. [4] that place adipose tissue and energy control in relation to the predisposition to AIS. It is speculated that leptin is linked to human central nervous system development, asynchronous neuro-osseous growth mechanism, and the dorsal shear mechanism. NCS = neurocentralsynchondrosis, GP = growth plate

\section{Components of cascade concept}

Leptin and central nervous system (CNS) development

We speculate that the leptin body composition effect of Clark et al. [4] links spinal cord development to the asynchronous neuro-osseous growth concept for AIS pathogenesis [8] for four reasons. Firstly, the decreased brain size of the $o b / o b$ mouse is evidently due to a developmental defect that can be corrected by leptin administration, indicating that leptin plays a role in brain growth and development [7]. Secondly, leptin in $o b / o b$ mice is reported to regulate the myelination of oligodendrocytes [9]. Thirdly, in primates, brain mass increases linearly with spinal cord mass, while neuron number in the brain increases with neuron number in the spinal cord raised to the power of 1.7 [10]. Fourthly, the low leptin effect on the CNS in AIS subjects $[3,11]$ may explain the different thinning pattern of the cerebral cortex observed in patients with AIS during adolescence, which may be primary (i.e. pathogenetic) or secondary (i.e. adaptation) to the development of scoliosis [12].

\section{Asynchronous neuro-osseous growth mechanism for AIS pathogenesis}

Using the multi-planar reconstruction technique of magnetic resonance imaging, $\mathrm{Chu}$ et al. [8]:

"....investigated the relative length of spinal cord to vertebral column, including ratios, in 28 girls with AIS (mainly thoracic or double major curves) and 14 age-matched normal girls. Also evaluated were cerebellar tonsillar position, somatosensory evoked potentials (SSEPs), and clinical neurological examination. In severe AIS compared with normal controls, the vertebral column is significantly longer without detectable spinal cord lengthening. They speculate that anterior spinal column overgrowth relative to a normal length 
spinal cord exerts a stretchintethering force between the two ends cranially and caudally, leading to the initiation and progression of thoracic AIS. They support and develop the Roth-Porter concept of uncoupled neuro-osseous growth in the pathogenesis of AIS which now they prefer to term 'asynchronous neuro-osseous growth'.

Lengths of the vertebral column were measured from the tip of $\mathrm{C} 2$ down to the inferior end plate of L5, and the spinal cord from the tip of $\mathrm{C} 2$ down to the conus medullaris [8].

\section{Conus medullaris and asynchronous neuro-osseous growth - hypothesis of impaired growth response of neuraxis to stretch with spinal growth creates a tether to anterior spinal overgrowth}

In AIS subjects, the mean and distribution of conus medullaris locations are similar to controls [13, 14]. During normal development, because of different relative rates of growth of the vertebral column and spinal cord, the level of termination of the spinal cord is constantly changing, particularly prenatally [15]. In the normal spine of children, the conus is reported to reach its adult level by 2 years of age at an average position of L1 to L2 $[15,16]$. We interpret subsequent spinal cord and cauda equina lengthening as a neural stretch adaptation to the linear growth of vertebrae. In the scoliosis subjects, measured by $\mathrm{Chu}$ et al. [8], where there was anterior spine overgrowth, the scoliosis was attributed to tethering of the relative anterior vertebral overgrowth by a normal length spinal cord (caudal part of neuraxis); also the seat of pathology which may extend into the brain stem neuraxis [17]. We explain the normal length spinal cord as resulting from impaired neuraxis growth in response to stretch due to a low leptin effect on neuraxis growth from age 10 years or earlier. This accounts for the finding of a spinal cord of normal length in AIS subjects with anterior vertebral [8] and skeletal overgrowth [18] driven by the hormones of puberty.

\section{Cranial expression of tension in the neuraxis}

Though not reported in the AIS subjects studied by Chu et al. [8], in the light of other findings [13, 14], the conus location was probably normal. If this be the case, then their finding of a normal length spinal cord with anterior spinal overgrowth suggests that the tension created in a relatively short spinal cord (neuraxis tether) by anterior vertebral growth is expressed, not caudally at conus level, but cranially in the upper cervical cord and medulla oblongata (as disturbed white matter) [17] and at the craniocervical junction (as low-lying cerebellar tonsils) [19].
The evidence for thoracic AIS [8] is consistent with the view that after 2 years of age, the cauda equina stretches with lumbar spine growth to produce a normal conus termination level. In contrast, the spinal cord neuraxis does not stretch fully and grow with the cervicothoracic spine, which causes traction on the upper cervical cord and brain stem. In the latter connection Kong et al. [17] write:

"The findings from this study are in agreement with previous findings showing abnormal somatosensory evoked potential readings occurring only above the C5-6 level in patients with adolescent idiopathic scoliosis; these findings might partially explain the pathophysiology of the neural pathway involved".

\section{Cascade concept and normal length of spinal neuraxis}

This interpretation applies to the Cascade Concept in which low circulating leptin levels impair growth of the spinal neuraxis. But how does this explain the reported normal length of the spinal cord [8]? Should the initial growth potential of the spinal neuraxis be coupled to that of the anterior spine for overgrowth [8], then impaired spinal neuraxis growth could produce a normal length spinal cord with anterior spinal overgrowth as reported by Chu et al. [8].

\section{Dorsal shear concept for AIS pathogenesis}

The speculation of Chu et al. [8] that the initiation and progression of AIS results from anterior vertebral column overgrowth through a lordoscoliotic maladaptation of the spine to the subclinical tether of a relatively short spinal cord, suggests that the neuraxis tethering may also act by altering the backward tilt of vertebrae in the lower spine within the dorsal shear concept of pathogenesis for AIS [20].

Castelein et al. [20] postulated that:

“... dorsal shear forces, acting exclusively upon specific regions of the human spine, contribute to rotational instability of the spine. Asymmetric loading of the posterior parts of the vertebrae then would lead to asymmetrical growth in all three planes of specific parts of vertebrae, according to the Hueter-Volkmann's law. Asymmetrical growth of the neurocentral cartilage of the vertebra, for instance, has been shown to lead to AIS-like deformities in growing pigs, and could explain the development and progression of the deformity in humans".

Schlosser et al. [21] conclude:

".....the spines of girls during the growth spurt are more posteriorly inclined, and thus rotationally less stable, compared to boys at the same stage of development, as well as compared to girls after the 
growth spurt. This may explain why initiation and progression of adolescent idiopathic scoliosis are more prevalent in girls around puberty".

We speculate that the leptin body composition effect is linked to central nervous system development and the asynchronous neuro-osseous growth mechanism. The latter, in combination with human upright posture, age and gender-related anatomical variants of vertebral backward tilt (dorsal shear concept), adolescent growth factors, the Hueter-Volkmann effect in vertebrae and vertebral bone mass abnormality, lead to AIS, possibly both initiation and progression of scoliosis curvatures.

\section{Hueter-Volkmann law}

The Hueter-Volkmann Law states that increased mechanical compression acting on growth plates impairs skeletal growth and reduced loading increases skeletal growth. Several concepts of AIS pathogenesis use the HueterVolkmann effect in their mechanisms [1, 22-24], each of which requires an initiating mechanism to deform the spine. The Cascade Concept for AIS includes the HueterVolkmann effect in its pathomechanisms (Fig. 1). This mechanism lies within the field of mechanobiology that in the skeleton includes the effects of Hueter-Volkmann, Pauwels and Wolff [24].

\section{Vertebral bone mass}

Once a scoliogenic mechanism, such as in the Cascade Concept, has initiated a spinal deformity, the presence in that subject of any reduced vertebral bone mass from known, (e.g. osteopenia, [25], melatonin-signalling dysfunction [26, 27], vitamin D [28] and possible calcium [29] deficiency), or from unknown causes, will facilitate progression of the scoliosis deformity.

In healthy subjects, both low fat mass and low lean mass are independent predictors of low bone mass [30, 31]. In individuals with scoliosis, Clark et al. [4] linked low lean mass to abnormalities of paravertebral muscle histology and electromyographic function. Here, we interpret the associations between low fat mass, low lean mass, bone mass and scoliosis as causal and determined in embryonic life.

\section{Developmental axial vertebral rotation}

The normal human spine in the transverse plane is not symmetrical. Between infancy and adolescence in the mid and lower thoracic spine, axial vertebral rotations (AVRs) convert from left to right $[32,33]$. We term this the left-right AVR conversion [34]. It reflects the most prevalent curve patterns in idiopathic scoliosis at different ages [32, 33].
Hypothesis of oscillating axial torsion and AVR conversion in normal development

We formulated the oscillating axial torsion hypothesis [35] in a study of upper limb length asymmetry in idiopathic scoliosis [36, 37]. The hypothesis is based on torsions of neural and skeletal structures in normal, preand post-natal human development. The postnatal leftright AVR conversion of the normal spine is contained within this oscillating axial torsion hypothesis where it is viewed as being determined by intrinsic developmental processes within growing axial structures; this is in contrast to the AVR conversion being interpreted as a mechanical adaptation of the spine to visceral asymmetry in the trunk [32, 33].

This controversy of mechanisms determining the AVR conversion was identified by Schlosser et al. [38] who suggested that while neurocentral synchondrosis (NCS) asymmetry and their fusion is related to pre-existent rotation of the spine; whether the NCS asymmetry is the cause, or is caused by, the pre-existent vertebral rotation, could not be determined. This controversy needs further consideration because, if normal intrinsic mechanisms determine the AVR conversion, then abnormality of these intrinsic mechanisms could be scoliogenic, not only in adolescence, but also in infancy [34].

\section{Putative thoracic axial rotation factors}

The Cascade Concept for AIS pathogenesis posits that the quantum of developmental axial vertebral rotation can be increased by one of at least four factors (Fig. 1): 1) contralateral cerebral hemisphere dysfunction $[39,40]$; 2) rib length asymmetry [41, 42]; 3) shallow chest acting through the ribs [43]; and 4) putative speech exhalation-associated scoliogenic mechanism acting through the ribcage [44]. We suggest that any such increase of axial vertebral rotation (transverse plane) when combined with backward vertebral tilt (sagittal plane) within the dorsal shear concept for AIS pathogenesis [20, 21] will facilitate the development of a scoliosis deformity.

\section{Embryonic origin of cascade concept for AIS pathogenesis}

To explain the association of components of body composition identifiable before the onset of scoliosis, Clark et al. [4] suggest that the origin of scoliosis affects a cluster of cell types, namely adipocytes and osteoblasts derived from the same progenitor cells (mesenchymal stem cells), and myoblasts derived from different progenitor cells (somitic myotome) (Fig. 2). Recent research suggests consideration is also given to visceral white adipose tissue arising from lateral plate mesoderm [45]. The involvement of cell types from different developmental origins suggests a process acting in embryonic life, 


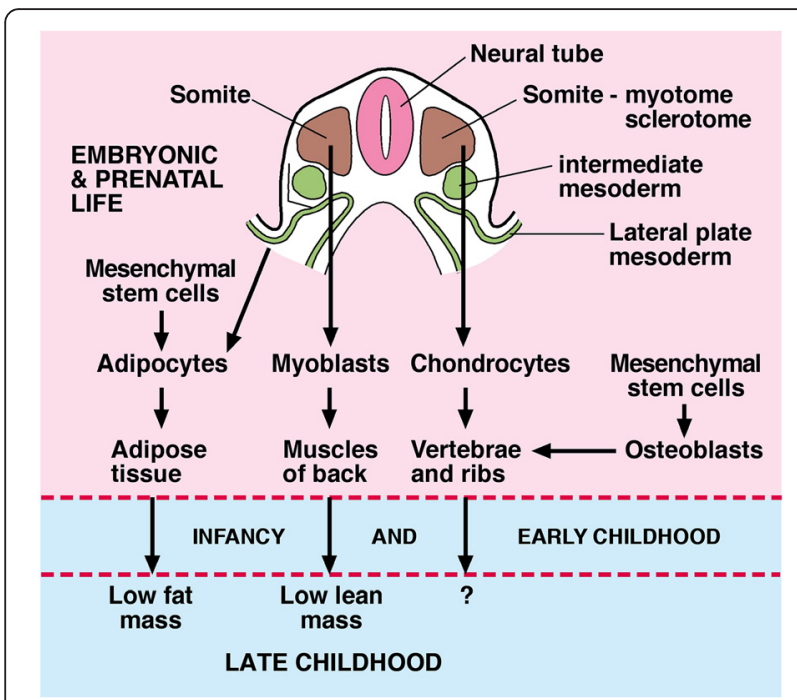

Fig. 2 Diagram from the description of Clark et al. [4] to show embryonic origin of cell types from progenitor cells suggested to be involved in AIS development. The cell lineages are from Gilbert [53] and Chau et al. [45]

probably environmental. This origin was also suggested from anthropometric studies [36].

We focus here on low fat mass and low leptin in relation to the Cascade Concept of AIS pathogenesis. How may abnormalities of adipocytes and other cell types arise? Although long form leptin receptor mRNA was expressed in the brain, pituitary, and other tissues, it was not detected in the spinal cord of pigs (gilts) [46]. This finding suggests the possibility that any such leptin effect on spinal cord growth may be indirect involving unknown factors.

\section{Sporadic AIS as a complex disease - genes and environment}

Sporadic AIS has been termed a Complex disease by not following the classical mode of Mendelian inheritance and for other reasons [3]. Complex diseases are caused by a combination of genetic, environmental, and lifestyle factors, mostly not yet identified; the vast majority of diseases fall into this category [47].

As a Complex disease, sporadic AIS will involve genetic, environmental and life style factors in development and growth [3]. Although environmental factors are involved in AIS aetiopathogenesis, no specific factor(s) has been identified $[48,49]$. A possible environmental mechanism has been evaluated in the first year of life; it involves a time lag (time-dependent reaction) between exposure and expression of the scoliosis phenotype [50].

\section{Conclusions}

Here we focus on two basic questions posed by the research of Clark et al. [4]:
- Does low fat mass and low leptin levels present at 10 years impair neuraxis growth between 10 and 15 years of age?

- May environmental factors acting on a susceptible genotype in early embryonic life determine AIS years later?

1. The observations of Clark et al. [4] relating to the scoliosis phenotype and endophenotype need confirming in other population or disease cohorts.

2. Rather than study the phenotype and endophenotype from birth, or even conception, knowledge may be facilitated by evaluating familial AIS in younger unaffected siblings of AIS girls in coordinated multicentre longitudinal studies.

3. Some biomechanical aspects of the Cascade Concept may be testable by numerical simulation. This method that involves three-dimensional reconstructions of the scoliotic spine has been used to study the effects of gravity loads, disc mechanical stiffness and anterior vertebral growth [51].

4. The numerical simulation method may be applied to components of the scoliotic spine in the sagittal and transverse planes, relating to both the asynchronous neuro-osseous growth mechanism and the dorsal shear concept for AIS pathogenesis.

5. As in the research of McMaster et al. [50] which focused on the first year of postnatal life, the process leading, after a time lag, to AIS might also affect susceptible embryos. This needs evaluating in epidemiological studies. Further epidemiological research is needed, including early pregnancy. The latter should include consideration of the perinatal microbiome [52].

Competing interests

The authors declare that they have no competing interests.

Authors' contributions

After a meeting between the authors in Bristol during January 2015 in which EC tutored the others about the scoliosis findings of ALSPAC, GB subsequently formulated the Cascade Concept and wrote the text, except for EC who added a section on independent predictors of low bone mass, PD edited and AM discussed the text. All authors approved the final version.

\section{Acknowledgements}

We thank Professor Jeremy Fairbank for initiating our meeting. Mrs RK Aujla proof read the texts $\mathrm{Mr} \mathrm{L}$ Cochrane drew the Figures.

\section{Author details}

${ }^{1}$ Centre for Spinal Studies and Surgery, Queen's Medical Centre, Nottingham University Hospitals Trust, Nottingham, UK. ${ }^{2}$ Academic Rheumatology, Musculoskeletal Research Unit, University of Bristol, Bristol, UK. ${ }^{3}$ University of Liverpool \& Staffordshire University, Staffordshire, UK. ${ }^{4}$ Department of Orthopaedic Surgery, King's Mill Hospital, Mansfield, UK. 


\section{References}

1. Burwell RG, Dangerfield PH, Freeman BJC. Concepts on the pathogenesis of adolescent idiopathic scoliosis. Bone growth and mass, vertebral column, spinal cord, brain, skull, extra-spinal left-right skeletal length asymmetries, disproportions and molecular pathogenesis. Stud Health Technol Inform. 2008;135:3-52

2. Wang WJ, Yeung HY, Chu WC, Tang NL, Lee KM, Qiu Y, et al. Top theories for the etiopathogenesis of adolescent idiopathic scoliosis. J Pediatr Orthop. 2011;31:S14-27.

3. Cheng JC, Castelein RM, Chu WC, Danielsson A J. Dobbs MB, Grivas TB, et al. Adolescent idiopathic scoliosis. Nature Reviews Disease Primers 2015, Article number 15030.

4. Clark EM, Taylor HJ, Harding I, Hutchinson J, Nelson I, Deanfield JE, et al. Association between components of body composition and scoliosis: a prospective cohort study reporting differences identifiable before the onset of scoliosis. J Bone Miner Res. 2014;29(8):1729-36.

5. Burwell RG, Clark EM, Dangerfield PH, Moulton A. Adolescent idiopathic scoliosis (AIS): cascade concept of pathogenesis. In: Proc Internat. France: Congress Clinical Anatomy, Rouen; 2015. p. 24-7. Clin Anat. in press (Abstract)

6. Burwell RG, Clark EM, Dangerfield PH. Moulton adolescent idiopathic scoliosis (AIS): embryonic origin of cascade concept of AIS pathogenesis. In: Proc Internat. France: Congress Clinical Anatomy, Rouen; 2015. p. 24-7. Clin Anat. in press (Abstract)

7. Steppan CM, Swick AG. A role for leptin in brain development. Biochem Biophys Res Commun. 1999;256(3):600-2.

8. Chu WCW, Lam WWM, Ng BKW, Lam T-P, Lee K-M, Guo X, et al. Relative shortening and functional tethering of spinal cord in adolescent scoliosis result of asynchronous neuro-osseous growth? summary of an electronic focus group debate of the IBSE. Scoliosis. 2008;3(8):48-7161-3.

9. Hashimoto R, Matsumoto A, Udagawa J, Hioki K, Otani H. Effect of leptin administration on myelination in ob/ob mouse cerebrum after birth. Neuroreport. 2013;24(1):22-9

10. Burish MJ, Peebles JK, Baldwin MK, Tavares L, Kaas JH, Herculano-Houze S. Cellular scaling rules for primate spinal cords. Brain Behav Evol. 2010; 76(1):45-59.

11. Qiu Y, Sun X, Qiu X, Li W, Zhu Z, Zhu F, et al. Decreased circulating leptin level and its association with body and bone mass in girls with adolescent idiopathic scoliosis. Spine. 2007;32(24):2703-10.

12. Wang D, Shi L, Chu WC, Burwell RG, Cheng JC, Ahuja AT. Abnormal cerebral cortical thinning pattern in adolescent girls with idiopathic scoliosis. Neuroimage. 2012;59(2):935-42

13. Sun X, Chu WC, Cheng JC, Zhu F, Zhu Z, Yu Y, et al. Do adolescents with a severe idiopathic scoliosis have higher locations of the conus medullaris than healthy adolescents? J Pediatr Orthop. 2008;28(6):669-73.

14. Hesarikia H, Azma K, Kousari A, Nikouei F. Magnetic resonance imaging investigations of position of conus medullaris in adolescent idiopathic scoliosis as a peripheral neuropathy. Int J Clin Exp Med. 2015;8(4):5918-24.

15. Barson AJ. The vertebral level of termination of the spinal cord during normal and abnormal development. J Anat. 1970;106(3):489-97.

16. Saifuddin A, Burnett SJ, White J. The variation of position of the Conus medullaris in an adult population. A magnetic resonance imaging study. Spine. 1998:23(13):1452-6.

17. Kong Y, Shi L, Hui SC, Wang D, Deng M, Chu WC, et al. Variation in anisotropy and diffusivity along the medulla oblongata and the whole spinal cord in adolescent idiopathic scoliosis: a pilot study using diffusion tensor imaging. Am J Neuroradiol. 2014;35(8):1621-7.

18. Cole AA, Burwell RG, Dangerfield PH, Grivas TB, Webb JK, Moulton A Anthropometry. Spine: state of the art reviews. Spine. 2000:4(2):411-21.

19. Chu WC, Man GC, Lam WW, Yeung BH, Chau WW, Ng BK, et al. A detailed morphologic and functional magnetic resonance imaging study of the craniocervical junction in adolescent idiopathic scoliosis. Spine. 2007:32(15):1667-74

20. Castelein RM, van Dieën $\mathrm{JH}$, Smit TH. The role of dorsal shear forces in the pathogenesis of adolescent idiopathic scoliosis - a hypothesis. Med Hypotheses. 2005;65(3):501-8.

21. Schlösser TP, Vincken KL, Rogers K, Castelein RM, Shah SA. Natural sagittal spino-pelvic alignment in boys and girls before, at and after the adolescent growth spurt. Eur Spine J. 2015;24(6):158-67.

22. Millner PA, Dickson RA. Idiopathic scoliosis: biomechanics and biology. Eur Spine J. 1996;5(6):362-73.
23. Veldhuizen AG, Wever DJ, Webb PJ. The aetiology of idiopathic scoliosis: biomechanical and neuromuscular factors. Eur Spine J. 2000:9(3):178-84.

24. Stokes IAF, Burwell RG, Dangerfield PH. Biomechanical spinal growth modulation and progressive adolescent scoliosis - a test of the 'vicious cycle' pathogenetic hypothesis: Summary of an electronic focus group debate of the IBSE. Scoliosis. 2006:1(16):7161-1-16.

25. Ishida K, Aota Y, Mitsugi N, Kono M, Higashi T, Kawai T, et al. Relationship between bone density and bone metabolism in adolescent idiopathic scoliosis. Scoliosis. 2015;10:9.

26. Moreau A, Wang DS, Forget S, Azeddine B, Angeloni D, Fraschini F, et al. Melatonin signaling dysfunction in adolescent idiopathic scoliosis. Spine. 2004;29(16):1772-81.

27. Azeddine B, Letellier K, da Wang S, Moldovan F, Moreau A. Molecular determinants of melatonin signaling dysfunction in adolescent idiopathic scoliosis. Clin Orthop Relat Res. 2007:462:45-52.

28. Batista R, Martins DE, Hayashi Li F, Lazaretti-Castro M, Puerta EB, Wajchenberg M. Association between vitamin D serum levels and adolescent idiopathic scoliosis. Scoliosis. 2014;9 Suppl 1:045.

29. Geddes L. Gone off. Our love of lactose has turned sour, but is it really true that milk could be bad for our health? New Sci. 2015;227(3031):33-7.

30. Clark EM, Ness AR, Tobias JH. Adipose tissue stimulates bone growth in prepubertal children. J Clin Endocrinol Metab. 2006;91(7):2534-41.

31. Zagarins SE, Ronnenberg AG, Gehlbach SH, Lin R, Bertone-Johnson ER. The association of lean mass and fat mass with peak bone mass in young premenopausal women. J Clin Densitom. 2010;13(4):392-8.

32. Janssen MM, Kouwenhoven JW, Schlösser TP, Viergever MA, Bartels LW, Castelein RM, et al. Analysis of preexistent vertebral rotation in the normal infantile, juvenile, and adolescent spine. Spine (Phila Pa 1976). 2011;36(7):E486-91.

33. Castelein RM. Pre-existent rotation of the normal spine at different ages and its consequences for the scoliotic mechanism. Stud Health Technol Inform. 2012;76:20-5.

34. Burwell RG, Dangerfield PH, Moulton A, Anderson SI, Grivas TB. Thoracic axial vertebral rotations show a conversion process in normal postnatal growth: development of scoliosis laterality and a scoliogenic lesion? Clin Anat. 2015;28(3):414 (Abstract).

35. Burwell RG, Dangerfield PH, Johnson F, Webb JK, Wilson YG. Anthropometric studies of normal and scoliotic children. In: Jacobs R, editor Pathogenesis of idiopathic scoliosis. Chicago, Illinois: Scoliosis Research Society; 1984. p. 27-44.

36. Burwell RG, Dangerfield PH, Vernon CL. Anthropometry and scoliosis. In: Zorab PA, editor. Scoliosis proceedings of a fifth symposium. London: Academic; 1977. p. 123-63.

37. Dangerfield PH, Burwell RG, Vernon CL. Chapter 14, anthropometry and scoliosis. In: Roaf R, editor. Spinal deformities. 2nd ed. Tunbridge Wells: Pitman Medical; 1980. p. 259-80.

38. Schlösser TP, Vincken $\mathrm{KL}$, Attrach $\mathrm{H}$, Kuijf HJ, Viergever MA, Janssen MM et al. Quantitative analysis of the closure pattern of the neurocentral junction as related to pre-existent rotation in the normal immature spine. Spine J. 2013:13(7):756-63.

39. Doménech J, Tormos JM, Barrios C, Pascual-Leone A. Motor cortical hyperexcitability in idiopathic scoliosis: could focal dystonia be a subclinical etiological factor? Eur Spine J. 2010;19(2):223-30.

40. Domenech J, García-Martí G, Martí-Bonmatí L, Barrios C, Tormos JM, Pascual-Leone A. Abnormal activation of the motor cortical network in idiopathic scoliosis demonstrated by functional MRI. Eur Spine J. 2011; 20(7):1069-1078.

41. Sevastik J, Burwell RG, Dangerfield PH. A new concept for the etiopathogenesis of the thoracospinal deformity of idiopathic scoliosis: summary of an electronic focus group debate of the IBSE. Eur Spine J. 2003;12:440-50.

42. Grivas TB. Rib index. Scoliosis. 2014:9:20

43. Kubota K, Doi T, Murata M, Kobayakawa K, Matsumoto $Y$, Harimaya $K$, et al. Disturbance of rib cage development causes progressive thoracic scoliosis: the creation of a nonsurgical structural scoliosis model in mice. J Bone Joint Surg Am. 2013;95(18):e130

44. Burwell RG, Dangerfield PH, Moulton A, Anderson SI, Grivas TB. Speech and the scoliogeny of right thoracic idiopathic scoliosis: brain and spinal cord enlargement in human evolution. Clin Anat. 2015:28(3):413-4. (Abstract).

45. Chau YY, Bandiera R, Serrels A, Martínez-Estrada OM, Qing W, Lee M, et al. Visceral and subcutaneous fat have different origins and evidence supports a mesothelial source. Nat Cell Biol. 2014;16(4):367-75. 
46. Lin J, Barb CR, Matteri RL, Kraeling RR, Chen X, Meinersmann RJ, et al. Long form leptin receptor mRNA expression in the brain, pituitary, and other tissues in the pig. Domest Anim Endocrinol. 2000;19(1):53-61.

47. Craig J. Complex diseases: research and applications. Nature Educ. 2008;1(1):184-27.

48. Burwell RG, Dangerfield PH, Moulton A, Grivas TB. Adolescent idiopathic scoliosis (AIS), environment, exposome and epigenetics: a molecular perspective of postnatal normal spinal growth and the etiopathogenesis of AIS with consideration of a network approach and possible implications for medical therapy. Scoliosis. 2011;6(1):26.

49. Grivas TB., Burwell RG, Dangerfield P H, Moulton A. Genetics, epigenetics and the scoliogeny of adolescent idiopathic scoliosis, how much is genetics and how much is it epigenetics as a new paradigm? Bone and Joint Journal (2014). http://www.boneandjoint.org.uk/content/genetics-epigenetics-andscoliogeny-adolescent-idiopathic-scoliosis-how-much-genetics-and (Accessed 22 July 2015).

50. McMaster ME, Lee AJ, Burwell RG. Physical activities of patients with adolescent idiopathic scoliosis (AIS): preliminary longitudinal case-control study historical evaluation of possible risk factors. Scoliosis. 2015;10:6.

51. Drevelle X, Lafon Y, Ebermeyer E, Courtois I, Dubousset J, Skalli W. Analysis of idiopathic scoliosis progression by using numerical simulation. Spine. 2010:35(10):E407-12.

52. Prince AL, Chu DM, Seferovic MD, Antony KM, Ma J, Aagaard KM. The perinatal microbiome and pregnancy: moving beyond the vaginal microbiome. Cold Spring Harb Perspect Med. 2015;16(5):6. pii: a023051.

53. Gilbert SF. Paraxial and intermediate mesoderm. Chapter 12. In: Developmental biology. Tenthth ed. Sunderland, MA, USA: Sinauer Associates, Inc; 2014. p. 415-48.

\section{Submit your next manuscript to BioMed Central and we will help you at every step:}

- We accept pre-submission inquiries

- Our selector tool helps you to find the most relevant journal

- We provide round the clock customer support

- Convenient online submission

- Thorough peer review

- Inclusion in PubMed and all major indexing services

- Maximum visibility for your research

Submit your manuscript at www.biomedcentral.com/submit 